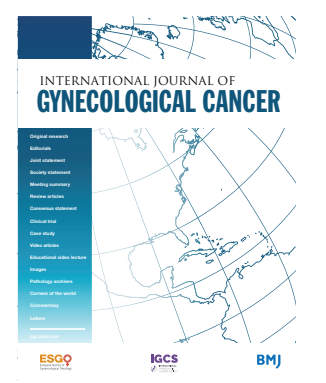

${ }^{1}$ Department of Obstetrics and Gynecology, Clinica Universidad de Navarra, Pamplona, Navarra, Spain

${ }^{2}$ Department of Obstetrics and Gynecology, Clinica Universidad de Navarra, Madrid, Spain

\section{Correspondence to}

Dr Nabil Manzour, Clinica Universidad de Navarra Departamento de Ginecologia y Obstetricia, Pamplona, Navarra, Spain; nmanzour@unav.es

Accepted 29 April 2021 Published Online First 24 May 2021

\title{
Intra-operative radiation therapy after a total lateral extended infralevator exenteration for recurrent cervical cancer
}

\author{
Nabil Manzour (D) , ${ }^{1}$ Daniel Vázquez-Vicente (D) , ${ }^{2}$ Isabel Carriles, ${ }^{2}$ Felix Boria (D) , \\ Enrique Chacon (D) , 'Luis Chiva (D) ${ }^{2}$
}

Total infralevator pelvic exenteration is a surgical therapeutic option in patients with central pelvic relapse of cervical cancer who have received previous chemoradiotherapy. ${ }^{1}$

In these patients, intra-operative electron radiotherapy can be an opportunity to consolidate the treatment in those with close or microscopically positive margins. ${ }^{2}$

In this Video 1, we show the case of a 75-year-old woman diagnosed with a stage IVA squamous cell carcinoma of the cervix, with rectum involvement and infiltration of the right parametrium. The workup did not show distant metastases beyond the pelvic disease.

She was treated with concomitant chemoradiotherapy and brachytherapy; one year after finishing the treatment, she started to perceive pelvic symptoms. An MRI demonstrated bilateral hydronephrosis and a recurrent pelvic mass infiltrating the right parametrium, the anterior vaginal wall, and the anterior aspect of the rectum. A PET-CT scan showed a hypermetabolic pelvic relapse without findings of distant disease.

The video shows the surgical approach to remove the recurrent disease, presenting a total lateral extended infralevator pelvic exenteration with its reconstruction. Additionally, after report of the specimen's frozen section showing close margins, the patient received intra-operative radiation therapy on the area with the highest risk of relapse.

Furthermore, in this case, we placed a breast implant under an omental flap to avoid the empty pelvic syndrome. The empty pelvic syndrome is one of the most frequent causes of morbidity in patients with pelvic exenteration. This syndrome is characterized by post-operative collections, abscess formation, prolonged ileus, intestinal obstruction, and small bowel fistulas. $^{3}$

Unfortunately, the implant became infected, and had to be removed through the perineal incision. Infection is one of the most frequent complications described using silicone gel implants. ${ }^{4}$

In conclusion, total lateral extended infralevator pelvic exenteration remains a potentially curative option to treat a pelvic relapse in patients with radiated cervical cancer. Additionally, intra-operative radiation therapy is a choice, still, with limited data, that might be considered to consolidate areas at high risk of relapse due to close or microscopically positive margins. A breast implant may be an option to contemplate, in selected patients, to fill the empty pelvis, although it is not free of potential complications, such as implant infection.
Check for updates

(C) IGCS and ESGO 2021. No commercial re-use. See rights and permissions. Published by BMJ.

To cite: Manzour N, Vázquez-Vicente $\mathrm{D}$, Carriles I, et al. Int J Gynecol Cancer 2021;31:1188-1189.
GYNECCOLOGICAL CANCER

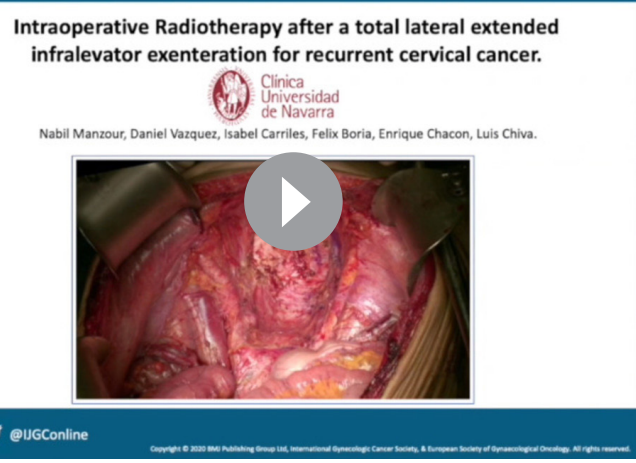

Video 1 Intra-operative radiation therapy after a total infralevator exenteration. 
Twitter Felix Boria @BoriaFelix and Enrique Chacon @Quique_ChC

Contributors All authors contributed either during surgery or during video processing.

Funding The authors have not declared a specific grant for this research from any funding agency in the public, commercial or not-for-profit sectors.

Competing interests None declared.

Patient consent for publication Not required.

Provenance and peer review Not commissioned; externally peer reviewed.

Data availability statement All data relevant to the study are included in the article.

\section{ORCID iDs}

Nabil Manzour http://orcid.org/0000-0002-4604-6042

Daniel Vázquez-Vicente http://orcid.org/0000-0002-9618-5606
Felix Boria http://orcid.org/0000-0002-4761-6190

Enrique Chacon http://orcid.org/0000-0001-8659-8602

Luis Chiva http://orcid.org/0000-0002-1908-3251

\section{REFERENCES}

1 Benn T, Brooks RA, Zhang Q, et al. Pelvic exenteration in gynecologic oncology: a single institution study over 20 years. Gynecol Oncol 2011;122:14-18.

2 Barney BM, Petersen IA, Dowdy SC, et al. Intraoperative electron beam radiotherapy (IOERT) in the management of locally advanced or recurrent cervical cancer. Radiat Oncol 2013;8:80.

3 Brown KGM, Solomon MJ, Koh CE. Pelvic exenteration surgery: the evolution of radical surgical techniques for advanced and recurrent pelvic malignancy. Dis Colon Rectum 2017;60:745-54.

4 Lalani T. Breast implant infections: an update. Infect Dis Clin North Am 2018;32:877-84. 